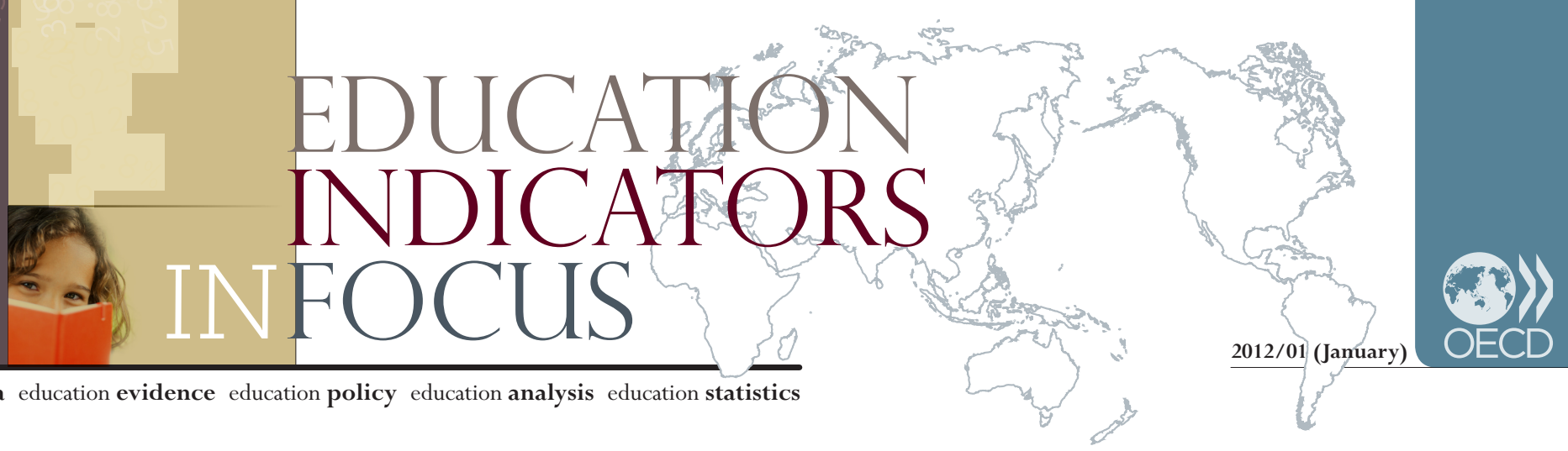

\title{
How has the global economic crisis affected people with different levels of education?
}

- Between 2008 and 2009, unemployment rates across OECD countries increased among people at all educational levels, but rose to especially troubling heights among people without an upper secondary education.

- In 2009, the average employment rate across OECD countries was much higher for individuals with a tertiary (i.e. higher) education - indicating a better match between the skills these people have and the skills the labour market required.

- Between 2008 and 2009, the earnings advantage for people with a tertiary education remained strong in OECD countries. In some countries, earnings inequality between people with a tertiary education and those without an upper secondary education widened even further.

Individuals' education levels had a big impact on how the crisis affected them. As the debt crisis in the Western world, stubbornly high unemployment rates, and stagnating economic growth in many countries create an uncertain outlook for 2012, it's a good time to take stock of how the global economic crisis that began in 2008 has affected people throughout the world. Within the OECD's member and partner countries, the lesson is clear: The economic downturn hit individuals with lower levels of education much harder.

At the height of the crisis, people with lower levels As the crisis ramped up in 2008 and continued in 2009, of education were much more likely overall unemployment rates among 25-64 year-olds to be unemployed... increased across the board in OECD countries. However, the impact was much more pronounced for individuals without an upper secondary education. Among this group, unemployment rates rose an average of 2.8 percentage points between 2008 and 2009, from an already high $8.7 \%$ to $11.5 \%$. Men and women in this group were particularly hard hit in Estonia, Ireland, Spain and the United States, where unemployment rates among people without an upper secondary education jumped 5 percentage points or more between these two years.

The impact of the crisis was somewhat milder among 25-64 year-olds with an upper secondary or postsecondary, non-tertiary attainment as their top education level. Among this group, unemployment rates in OECD countries rose an average of nearly 2 percentage points between 2008 and 2009 , from $4.9 \%$ to $6.8 \%$. In several countries - Estonia, Ireland, the Slovak Republic, Spain, and Turkey - unemployment rates reached 10\% or more among people with this level of education, and nearly did so in the United States as well.

By contrast, people with a tertiary (i.e. higher) education fared much better than their less-educated counterparts during the thick of the global recession. Overall, unemployment rates among 25-64 year-olds with this level of education in OECD countries rose just 1.1 percentage points between 2008 and 2009, from $3.3 \%$ to $4.4 \%$ less than half the spike in unemployment among individuals without an upper secondary education. 
Notably, 2009 unemployment rates remained at $5 \%$ or less for tertiary-educated individuals in 24 out of 34 OECD countries, as well as the partner country Brazil. Moreover, 2009 unemployment rates for this group surpassed $8 \%$ in only two OECD countries - Spain and Turkey.

\section{Change in unemployment rates, by level of education (2008-09)}

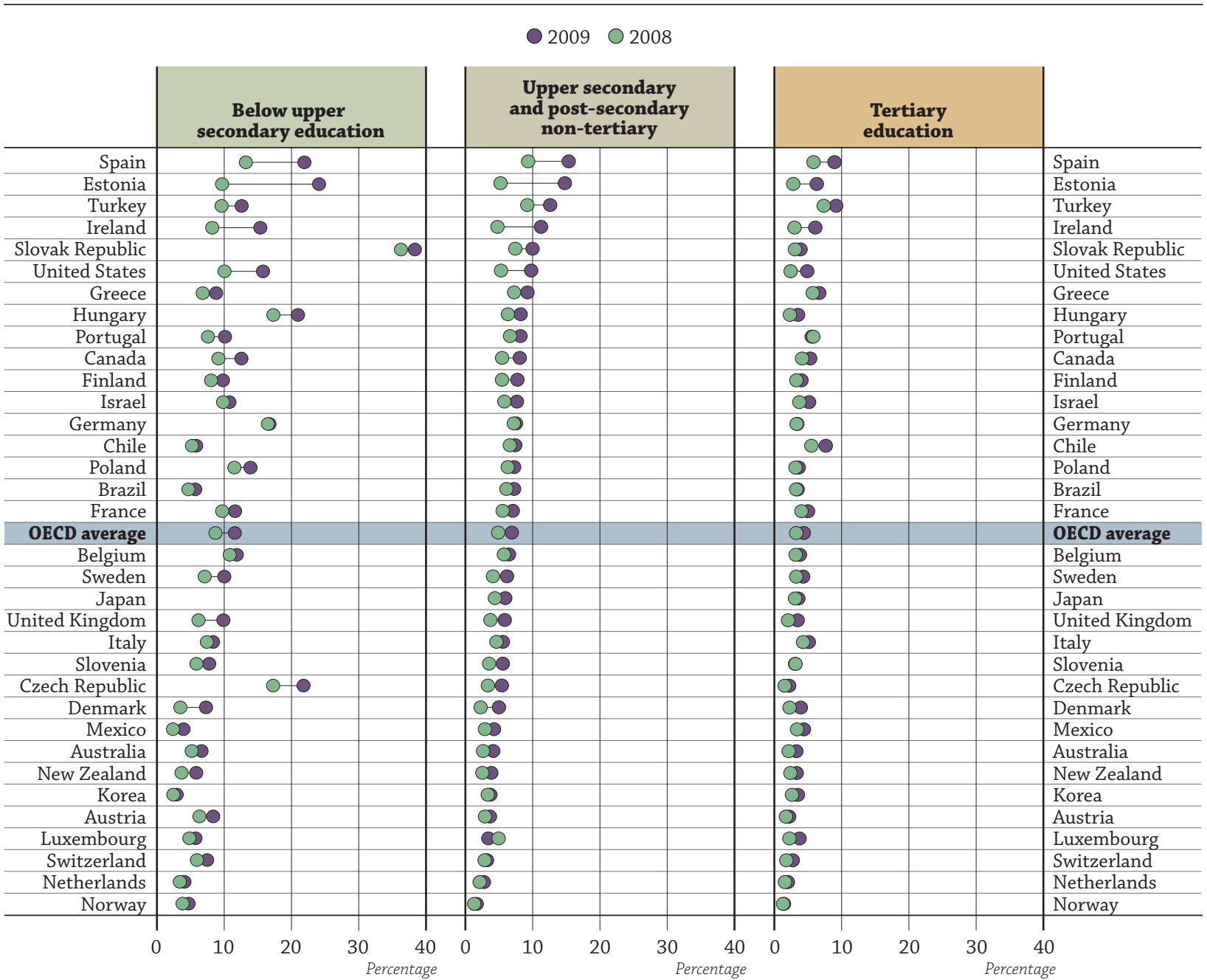

Countries are ranked in descending order of the unemployment rate in 2009 for individuals with upper secondary and post-secondary non-tertiary education. Source: Education at a Glance 2011: OECD Indicators, Indicator A7 (www.oecd.org/edu/eag2011).

...while people with higher levels of education were much more likely to be in steady employment.

Employment figures underscore the large competitive advantage that people with higher levels of education have in the labour market - both in general and in difficult economic times. On average across all OECD countries, $83.6 \%$ of $25-64$ year-olds with a tertiary education were employed in 2009 , compared to $56.0 \%$ of 25-64 year-olds without an upper secondary education - a difference of 27.6 percentage points. In the Czech Republic, Hungary, Poland and the Slovak Republic, this gap was more than 40 percentage points, while $6 \%$ in Iceland, Korea, and New Zealand, it was 15 percentage points or less. 




\section{The employment rate vs. the unemployment rate}

Despite common misconceptions, the employment rate and the unemployment rate are not directly related to each other. The employment rate refers to the number of people in employment as a percentage of the population of working age. The unemployment rate measures the number of individuals who are without work, actively seeking employment, and available to start work as a percentage of the civil labour force, during a specific reference period.

Similarly, tertiary-educated individuals were employed at higher rates than people with an upper secondary or post-secondary, non-tertiary education. On average across all OECD countries, $74.2 \%$ of 25-64 year-olds at these educational levels were employed in 2009 - a difference of 9.5 percentage points from the employment rate among tertiaryeducated individuals. While a number of factors, most notably, women's participation in the labour force, contribute to variations in employment rates among countries, higher employment rates for people with more education point to a better match between the skills these individuals possess and the skills the labour market demands, even during periods of economic crisis.
The earnings advantage for the typical employee with a tertiary education held strong during the crisis.

\section{Earnings premiums and penalties, by level of education} (2008-2009)

Total Population, 25-64 year-olds

(compared to average earnings for people with an upper secondary or post-secondary, non-tertiary education)

\begin{tabular}{l|c|c} 
Country Average* $^{*}$ & 2008 & 2009 \\
\hline Tertiary & $+56 \%$ & $+57 \%$ \\
\hline Below upper secondary & $-23 \%$ & $-23 \%$ \\
\hline
\end{tabular}

${ }^{*}$ Average includes $14 \mathrm{OECD}$ countries with available data for both years.

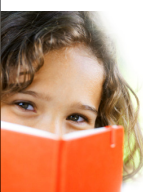


